\title{
The Role of Molecular Taxonomy in Uncovering Variation within Crayfish and the Implications for Conservation
}

\author{
QUinton BURnHAM ${ }^{1, *}$ AND KaTHRYN L. DAWKINS ${ }^{2}$ \\ ${ }^{1}$ Centre for Ecosystem Management, School of Natural Sciences, Edith Cowan University, 270 Joondalup Drive, \\ Joondalup, Western Australia 6027, Australia. *Corresponding Author._q.burnham@ecu.edu.au \\ ${ }^{2}$ Australian Rivers Institute, Griffith School of Environment, Griffith University, Parklands Drive, Gold Coast, \\ Queensland 4222, Australia
}

\begin{abstract}
Freshwater species in general (and crayfish specifically) often have limited ranges with high species endemism within, and species turnover between, catchments. Freshwater species also face ever-increasing threats, and genetic diversity (both at and below the species level) is being lost as a result of these threats. Molecular taxonomy provides a tool by which this diversity can be rapidly (and relatively cheaply) uncovered before it is lost. Identifying previously unrealised diversity within crayfish via molecular techniques can act as a stimulus to further taxonomic investigations and conservation efforts. Specific examples are given from Australian crayfish, where molecular data have highlighted significant genetic diversity, which may correspond to previously overlooked morphological variation. We hope these examples can promote the undertaking of wide scale molecular revisions of as many crayfish taxa as possible, looking for any previously unrecognised lineages within currently described species (akin to ESUs) that warrant further revision. Beyond this, we advocate that these lineages should be afforded conservation consideration in order to buy time for more thorough reviews to be completed. [Keywords.-Australia, conservation, Engaewa, ESUs, freshwater crayfish, molecular systematics, taxonomy, Tenuibranchiurus].
\end{abstract}

Submitted: 31 March 2012; Accepted: 15 October 2012, Published: 15 February 2013

\section{INTRODUCTION}

In the region of 125,000 species of freshwater animals have so far been described; this represents $\sim 9.5 \%$ of all known animal species, despite freshwater covering just $0.8 \%$ of the Earth's surface area (Dudgeon et al. 2006; Balian et al. 2008; Strayer and Dudgeon 2010). These figures have led some authors (such as Strayer and Dudgeon 2010) to suggest that fresh waters as a whole should be considered as a hotspot for biodiversity. Whilst a few freshwater species have large geographic ranges, many do not, often to the point where they are found in just a single lake or drainage basin (e.g., Rossiter and Kawanabe 2000; Dudgeon et al. 2006; Strayer 2006). These small ranges reflect the insular nature of freshwater habitats, and restricted gene flow is often observed in freshwater species because of the isolating nature of riverine systems (DeWoody and Avise 2000; Ward et al. 2005; Hughes 2007). This has led to the evolution of biotas with high endemism and high species turnover between basins (Strayer and Dudgeon 2010).

Although freshwater ecosystems are often relatively understudied in comparison to terrestrial and marine systems, it seems that biodiversity within freshwater ecosystems is at particular risk (e.g., Sala et al. 2000; Dudgeon et al. 2006; Strayer 2006; Strayer and Dudgeon 2010). Fresh waters are naturally fragmented into drainages and products of human activities have enormously increased habitat fragmentation (Strayer and Dudgeon
2010). Where human activities have eliminated populations and reduced the ranges of species, the combination of fragmentation and limited dispersal abilities means freshwater species are unable to migrate across the landscape to re-establish local populations that have been extirpated, or respond to climate change (Strayer and Dudgeon 2010). It has been shown that the genetic structuring present between catchments often seems to support the Death Valley zoogeographic model (sensu Meffe and Vrijenhoek 1988), whereby individuals are unable to migrate between catchments and, therefore, populations become highly differentiated without the homogenising influence of inter-population gene exchange (Meffe and Vrijenhoek 1988; Huey et al. 2010). Each of these populations will, over time, become a unique genetic entity as they evolve in isolation.

Conservation and management decisions should ideally be based on sound knowledge of the taxonomy, biological diversity, and distributions of endemic species in particular (Linkem et al. 2010). Outdated or inaccurate taxonomy hampers our attempts to understand the biodiversity of a region, potentially leading to poorly informed conservation planning (Linkem et al. 2010). It has been noted (e.g., Dawkins and Furse 2012) that there is often an incomplete understanding of the true diversity within well-known groups, and also that very high group- and species-level conservation values can be easily overlooked. Examples provided by Dawkins and 
Furse (2012) include cryptic diversity in a number of well-studied freshwater macroinvertebrate groups (e.g., Baker et al. 2004), and cryptic genetic divergence in the world's largest freshwater crayfish species Astacopsis gouldi Clark (Sinclair et al. 2011).

Over the last few years, numerous authors have made mention of a "taxonomic crisis" which they believe is occurring, primarily due to a lack of specialists (particularly for specific taxonomic groups and geographic regions) combined with insufficient funding (Godfray 2002; Mallett and Willmott 2003). This crisis has fuelled a debate about how best to make use of resources, which, in turn, has led to much concern over the state of taxonomy and nomenclature, arising largely from differing views on how the burgeoning field of molecular systematics should be applied to species delimitation. It is important to stress at this point that the authors are not arguing for the prominence of any one data type over another, nor entering the debate around how candidate species based on molecular data should be incorporated into the Linnaean naming system (if at all), we are not advocating nor condemning the concept of DNA barcoding and we will not be suggesting guidelines by which species should be recognised. What we seek to promote is wide scale molecular revisions of as many crayfish taxa as possible, looking for any previously unrecognised lineages within currently described species (akin to ESUs) that warrant further revision and that these lineages receive conservation consideration in order to buy time for more thorough reviews to be completed.

Traditional taxonomy relies on the observation of shared morphological features, which can be used to classify the organism into a species, genus, family, and so on. Despite being the foundation of taxonomy, patterns of morphological character states have potentially serious flaws when characters arise via homoplasy (e.g., parallel evolution, convergent evolution, secondary loss). The addition of characters based on genomic data provides an alternative line of evidence that can contribute to determining the systematic relationship of organisms and assessing taxonomic rank (Nei and Kumar 2000). This has led to the development of 'molecular taxonomy' that has a number of advantages over traditional taxonomy, such as the greater speed of application and the recognition of morphologically cryptic species (Hebert et al. 2003; Stoeckle 2003).

Molecular taxonomy does, of course, have its own weaknesses, arising from factors such as genetic polymorphisms, introgressive hybridization, and incomplete lineage sorting, as well as the obvious caveat that it does not (currently and possibly ever) allow for species identification in the field. Nevertheless, the potential for a form of molecular taxonomy to speed up the process of identifying and naming species is of considerable importance, as it has been recognised that there is a shortage of taxonomists to the point where the mean yearly rate of species description has been called "depressingly slow" (Stork 1994).

The relative merits of molecular versus morphological methods in taxonomy has, at times, been hotly debated, however, increasingly authors are proposing that the two should not be seen as competing, but rather complementary. Dayrat (2005) and Will et al. (2005) concurrently, though unknowingly, both coined the term integrative taxonomy for the process of actively combining as many different data sets as possible (e.g., from phylogeography, comparative morphology, population genetics, ecology, development, behaviour, etc.) in order to accurately delineate and name species (although see Valdecasas et al. (2008) for important clarifications on the differences between the two proposals). Whilst achieving the most accurate taxonomy possible is a highly desirable goal, the adoption of a form of integrative taxonomy, whereby multiple data sources are analysed, will, if anything, slow down the formal recognition of new species. This is where a preliminary molecular screening, particularly of poorly known or morphologically complex groups, may help direct efforts to where they are most needed and provide a conservation option before it is too late.

One group of organisms that requires attention, both in terms of issues related to taxonomy and conservation, is freshwater crayfish. Currently there are over 640 described species of freshwater crayfish (Crandall and Buhay 2008) with more species being described every year. In 2010, an assessment of the world's freshwater crayfish was completed for the IUCN Red List of Threatened Species, which established freshwater crayfish as one of the world's five most threatened groups of animals (Ram and Dewhurst 2008; IUCN 2011). The major threat classes (as defined by Horwitz 2010) influencing the persistence of freshwater crayfish species all either stem directly from, or are at least compounded by, anthropogenic activities and include water regime change, climate change, habitat quality change, biological invasions, and human predation. The example provided by freshwater crayfish shows that fresh waters can be seen as a hotspot of both endangerment and biodiversity and makes the need for rapid action obvious.

\section{Crayfish Taxonomy and Conservation}

Crayfish taxonomy has often been in a state of flux, with different understandings of morphological and habitat variation within freshwater crayfish common. An example of how examining additional data and adding multiple data types (e.g., morphology, ecology/habitat, molecular) can affect our best estimate of taxonomy comes from the (now defunct) Tasmanian endemic genus Parastacoides. In 1936, Clark erected the monotypic genus, Parastacoides, with Astacus tasmanicus Erichson designated the type specimen; however, in 1939 Clark added another two species, Parastacoides inermis Clark and Parastacoides insignis Clark. Riek (1951) described an additional two species Parastacoides setosimerus Riek and Parastacoides leptomerus Riek but sixteen years later synonymised $P$. setosimerus and Parastacoides tasmanicus (Erichson) whilst adding two more species: Parastacoides sternalis Riek and Parastacoides pulcher Riek (Riek 1967a). Based on a numerical phenetic study, Sumner (1978) reviewed the genus and identified three groups, to which he gave sub-specific rank: Parastacoides tasmanicus tasmanicus (Erichson) (P. tasmanicus, P. pulcher, P. leptomerus, $P$. setosimerus), Parastacoides tasmanicus inermis (Clark) (P. inermis, P. sternalis Riek), Parastacoides tasmanicus insignis (Clark) (P. insignis): thus reducing the number of species back to one. Ecological work by Richardson and Swain (1980), however, suggested that habitat and morphological variation was more complicated than previously realised and was inconsistent with the recognition of only a single species of Parastacoides 
divided into three subspecies. Most recently, using a combination of molecular and morphological analyses, Hansen and Richardson (2006) divided Parastacoides into fourteen species within two newly erected genera Ombrastacoides Hansen and Richardson and Spinastacoides Hansen and Richardson.

Studies utilising genetic data to examine the systematics of freshwater crayfish with morphology that is ambiguous or difficult to interpret suggest that morphologically based taxonomic studies of freshwater crayfish need to be interpreted with caution (e.g., Horwitz et al. 1990; Zeidler and Adams 1990; Campbell et al. 1994; Austin and Knott 1996). As noted by Austin and Knott (1996) the need for caution is because taxonomic characters may be more variable than realised, morphological and habitat differences may not equate with specific distinctions, and genetically distinct species need not be morphologically distinct.

Morphological plasticity has been demonstrated in decapod crustaceans. For example, the Australian freshwater prawn Macrobrachium australiense Holthuis shows rostral morphology (a character used widely in decapod taxonomy) that is strongly influenced by environment (Dimmock et al. 2004). Examples from freshwater crayfish include those provided by Austin (1996) and Austin and Knott (1996), which suggest that the genus Cherax may display morphological plasticity in relation to environmental factors. Cherax crassimanus Riek, Cherax quinquecarinatus (Gray) and Cherax preissii Erichson each utilize an extremely wide range of freshwater habitats, ranging from deeper, permanent rivers to semi-permanent swamps (Austin and Knott 1996). Austin and Knott (1996) found a direct correspondence between habitat variation and a large component of the morphological variation observed both within and between species. The morphological variation found to correspond to habitat variation was made up of a diverse range of traits, including several that have been considered previously (Riek 1967b, 1969) to be of taxonomic importance (Austin and Knott 1996). A similar correlation of attributes to those reported by Austin and Knott (1996) was noted by Hobbs Jr. (1975) among North American freshwater crayfish species, however Austin and Knott (1996) were the first to show such a relationship within species.

The implication of these insights is that the conventional approach to the taxonomy of freshwater crayfish, where small anatomical differences are assumed to be reliable guides to specific distinctions, both in the Southern Hemisphere (e.g., Clark 1936; Riek 1951, 1956, 1967a,b, 1969, 1972; Sumner 1978; Swain et al. 1982; Morgan 1986, 1988; Hobbs Jr. 1987) and in the Northern Hemisphere (Hobbs Jr. 1989 and references therein) may be flawed and therefore so too the existing systematics of freshwater crayfish. Furthermore, the presence of potential morphological plasticity within freshwater crayfish suggest that, where habitat characteristics have been used as supporting information for the delineation of freshwater crayfish (based on an assumption that crayfish species tend to occupy narrow and distinct habitats), these errors may have been compounded (Austin and Knott 1996). Clearly the use of such convergent characteristics interpreted as the result of descent from a common ancestor will result in the construction of erroneous taxonomies and phylogenies (Fetzner and Crandall 2002).
Addressing taxonomic and phylogenetic questions via the utilization of non-morphological characters (e.g., serology and genetics) has a long history in astacological research (e.g., Clark and Burnet 1942; Patak and Baldwin 1984; Patak et al. 1989; Austin 1996; Austin and Knott 1996) and more recently molecular data has been acknowledged in playing an important role in conservation biology through ensuring accurate definitions of species boundaries, facilitating detection of cryptic species, and providing boundaries for management units within species (Cataudella et al. 2010). It has been noted that we are currently facing a global biodiversity crisis with a rapid loss of diversity occurring in all environments and at all levels, from ecosystems to genes (Browning et al. 2001), with population declines and species' extinctions occurring at an unprecedented rate (Dirzo and Raven 2003; DeSalle and Amato 2004; May 2010). It is evident that the scale of biodiversity loss globally makes the conservation of all threatened species virtually impossible; therefore certain units (whether evolutionarily significant units (ESUs), species, regions, etc.) must be made priorities.

In a much-cited paper, Moritz (1994) suggested that molecular markers can identify ESUs or management units (MUs) for conservation, although other authors (such as Crandall et al. 2000) argue that ESUs should not be defined solely by genetic isolation, rather other characteristics such as adaptive diversity should be the defining feature. Despite this debate the definition of Moritz (1994) (i.e., MUs being sets of populations with distinct allele frequencies, and ESUs being sets of populations distinguished by reciprocal monophyly of mtDNA variation, and stronger divergence in the frequencies of nuclear alleles) is often employed, at least as a starting point. It can be argued that the identification and protection of these genetically distinct groups is vital as genetic diversity underpins evolutionary success and resilience (Sgrò et al. 2011).

An example of the application of recognising ESUs in relation to Australian freshwater crayfish comes from Cherax tenuimanus (Smith), commonly known as 'marron'. Studies of allozyme variation within and between Cherax species from south-west Western Australia revealed that the marron is represented by two genetically distinct lineages (Austin 1979, 1986; Austin and Knott 1996). Nguyen et al. (2002), examined the genetic variation within the mtDNA gene region $16 \mathrm{~S}$ and confirmed the existence of two distinct genetic groups and recommended the recognition of ESUs was warranted. One lineage (or ESU) was found only in the Margaret River in southern Western Australia, whereas all other populations evaluated belonged to a single wide-spread lineage. The Margaret River ESU was later elevated to species status and, as the type specimen was from this group, retained the name $C$. tenuimanus with all other marron becoming known as Cherax cainii Austin (in Austin and Ryan 2002).

Certain freshwater habitats in Australia have a high proportion of short-range endemics (SREs, sensu Harvey 2002), with many species restricted to individual river systems or drainage basins (Harvey 2002). Many of these SREs also represent relictual lineages of Gondwanan affinities where permanent freshwater ecosystems have provided stable enough environments for species to persist (Harvey 2002). These SREs can provide a focal point for 


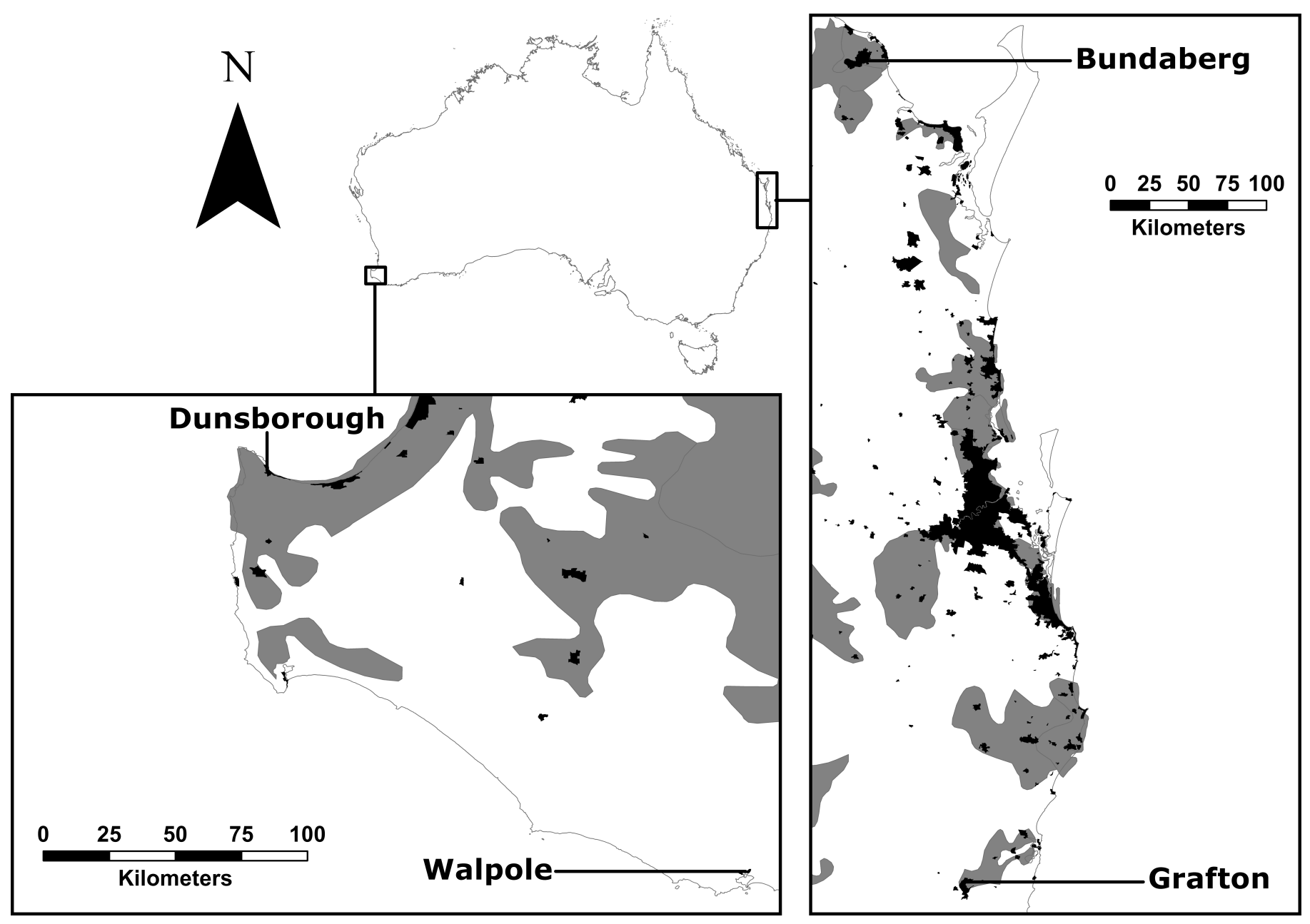

Figure 1. The distribution of the two case study genera (Engaewa in south-western Australia and Tenuibranchiurus in central-eastern Australia) are shown in the detailed boxes. Also shown is the approximate extent of habitat alteration in both regions since European colonisation (represented by the grey shading) and the major urban areas (shown in black). Both genera occur only within approximately $20 \mathrm{~km}$ of the coastline.

conservation efforts, particularly where they also represent relictual lineages. Relict species are particularly prone to extinction as they generally exhibit narrow habitat tolerance (Henle et al. 1996) and rare species (geographically restricted) often demonstrate poor dispersal abilities (Gaston and Kunin 1997). Compounding this problem is the fact that increased fragmentation resulting from human activities severely limits species' abilities to respond to deleterious conditions by dispersing (Edwards et al. 2007).

Most SREs have a small body size, often-specialised behaviour, and many of them are confined to specific restricted microhabitats, which may not be readily perceived by broad scale surveys (Main 1996). Thus, they have often been overlooked entirely or not enough populations have been studied to accurately delineate the appropriate species groupings. It has been argued that geographically rare species tend to consist of several discrete populations (Maurer and Nott 1998) and have poor dispersal (Gaston 1994; Gaston and Kunin 1997), and are therefore expected to have higher speciation rates. Therefore, it can be seen that the potential exists for there to be many entirely overlooked species (or ESUs) that could be identified either through further field collections, or from museum collections, if the time and effort can be allocated. This has been proven for at least two freshwater crayfish genera in Australia and these examples are outlined below.

\section{Case Studies}

Both Engaewa Riek and Tenuibranchiurus Riek are restricted to coastal regions of Australia (Engaewa in the south-west and Tenuibranchiurus in the central-east) and the authors are currently reviewing their taxonomy. Both of these regions have undergone heavy environmental alteration (Figure 1). The coastal regions of Australia in general have become increasingly urbanised, which has been recognised as threatening many of the remaining habitat fragments that Tenuibranchiurus occupies (Davie 2007; Coughran et al. 2010). It has also been recognised that the aquatic biodiversity of south-western Australia, particularly in the coastal margins, is facing significant and increasing survival pressure due to large-scale human endeavours (Horwitz et al. 2008) including agriculture, urbanization, groundwater extraction, and mining (Burnham et al. 2012).

Engaewa and Tenuibranchiurus are both small crayfish belonging to the strong burrowing clade of Australian crayfish (as first suggested by Riek (1972) and later refined by Horwitz (1988)). 
They each exist in regions where their range is highly fragmented and effectively have no opportunity to disperse between areas of suitable habitat (Burnham 2005; Coughran et al. 2010; Dawkins et al. 2010). As mentioned previously, these characteristics make them likely to be both highly speciose and also highly imperilled. There is a very obvious need, therefore, to review their taxonomy, and to highlight areas that contain unique genetic diversity that may likely be lost in the near future unless conservation measures are put in place.

Considerable morphological variation exists within the species descriptions for Engaewa, whereas for the single Tenuibranchiurus species, there is little mention of any variation. The situation for both of these genera suggests that morphological revisions are warranted and are, in fact, currently underway. As discussed previously, it can be difficult to weigh the relative merit of morphological character states and to decide which represent variation within a species, and which can be considered diagnostic, for some crayfish groups. The burrowing habit of the crayfish in this study increases this concern, as it results in a number of convergent morphological changes, such as alteration of the chelae orientation, cephalothorax vaulting, abdominal reduction, and reduction in overall spination. Thus, a comparison of the molecular delineated species groupings with a large range of morphological characters may help to highlight certain characters that appear to be less likely to be confounded by other factors such as size, sex, reproductive state, plasticity, and homoplasy.

The utilisation of molecular methodology has suggested where diversity may be found within these genera, which provides a platform for the speedy implementation of conservation measures through the recognition of ESUs. The adoption of this approach could buy time for further studies into differences (morphological, behavioural, ecological, etc.) between populations that may support specific (or even generic) level recognition, thus providing the taxonomic certainty and biological data currently required for the formal conservation listing approach.

\section{Engaewa Riek}

Riek (1967b) described the first three Engaewa species, each from a single locality, and in 2000, Horwitz and Adams described an additional two species, based on allozyme and morphological data, whilst noting that there was probably still unaccounted variation present within particular populations. Two lineages exist that likely warrant species listings: one has been suggested by Burnham et al. (2012), and the other is from the author's (QB) unpublished data. Both of these were initially identified through DNA sequence data and later morphological characters were uncovered that further supports their status as species. Of these two potential species, one represents the splitting of a widespread and relatively common species and the other is composed of a single population that had not been previously reviewed. A third possible new species was highlighted by Burnham et al. (2012) but, as it was only represented by two specimens from a single population and most closely related to E. pseudoreducta, which is listed as Critically Endangered at both State and Federal levels, it was included as a member of this species until further review can occur.
These examples suggest that screening a large number of populations with molecular techniques is valuable for two reasons. Firstly, if a species is apparently common and widespread in comparison to its congeners it is potentially less likely to be revised, as focus may be given to the species that are threatened and/or persisting in a more dynamic environment. Though intuitive, it is still important to note that once the presence of two lineages has been recognised, the range of each (candidate) species is obviously less than the original, thus their conservation status should be reassessed, as the geographic partitioning may be far from equal, both in terms of size and quality of habitat, and the likelihood of threatening processes.

In the second scenario, where a species exists in only a single (or very few) population(s), it can easily continue to be overlooked in studies that examine only a subset of the possible material (whether collected specimens, known populations or potential habitat). An implication of discovering a species existing as a single population only is that any new population found could represent a new species and the geographic distribution of known species is not a suitable surrogate for species identification (which had been largely assumed for this genus previously). This possibility suggests that enough morphological material needs to be examined from every population to decide if there are any overlooked species in current collections. Any subsequently uncovered population would also need to be reviewed to see if the character states found are unique or within the range of variation present in the current species description. This is likely to be far too time-consuming and often requires a specialist understanding of the taxa being reviewed.

\section{Tenuibranchiurus Riek}

Currently only one species is described in the genus, Tenuibranchiurus glypticus Riek. Horwitz (1995) suggested this should be increased to three species on the basis of electrophoretic and geographical differences (although the data were never published), and more recently Dawkins et al. (2010) proposed at least one additional species based on mtDNA data. In their study, high levels of genetic variation in seven screened populations suggested the presence of at least five ESUs. Further examination, using both mtDNA and nDNA as well as additional populations (author's unpublished data (KD)), provides support for the previously identified ESUs and suggests they are candidate species (with potential further additions, including the possible division of this group in to two genera) due to the very high levels of genetic diversity. A morphological revision is currently underway, which appears to support these findings. The finding of numerous genetic groups within this genus is not surprising considering the highly fragmented nature of the habitat throughout the range of these crayfish and the complex geographic history of the region.

As previously mentioned, much of the coastal region that Tenuibranchiurus occupies is under threat from urbanisation, and as there is currently only a single species recognised there would be little, if any, protection afforded to individual populations. As each population has been shown to be essentially a unique genetic entity, the loss of any population is significant in the conservation of the overall genetic diversity within the genus. Threats rarely 
occur homogeneously across a wide geographic area, therefore some populations are likely to be under more intense pressure than others. However, by identifying ESUs (and possibly candidate species), regions containing the most highly divergent lineages can be flagged for conservation management. The ability of molecular methodology to rapidly highlight diversity (versus a full morphological revision) in this genus potentially allows lineages to be identified and located in time for their preservation to be considered as part of planning for further development in the region.

\section{CONCLUSIONS}

Both of the above case studies provide examples where complex situations can be effectively managed by conducting a wide-scale molecular analysis of the genus in question, to identify any populations that have significant genetic divergence. Once this is completed a more detailed analysis of these populations in particular can occur, in order to improve the current taxonomy. When new populations are uncovered there is then the option to attempt to identify the species present via a traditional taxonomic key, assuming one is available. If this is not possible, due to either the inadequacy of the key or lack of expertise of the person attempting to use it, they can be screened via a molecular marker (DNA barcoding approach) by virtually any researcher in any lab anywhere in the world, to see if they are likely to represent significant new variation, without the need of a specialist.

The use of molecular methods, such as DNA sequencing, to identify unrealised diversity has grown rapidly. It is now possible to screen a large number of populations relatively quickly and cheaply when compared to the effort required to undertake full morphological reviews. A molecular approach also provides additional advantages as it is generally non-lethal, samples can be stored for long periods of time without degrading and there is no need (at least initially) for specialist expertise of the taxa being reviewed. In addition to potentially highlighting ESUs and candidate species, the application of molecular methodology has a number of other possible benefits. Examination of genetic structure can substantially add to the current information available by providing effective populations sizes, sex ratios, and possibly measures of inbreeding or migration. On the basis of falling costs, greater accessibility, ease, speed, and success of molecular biology techniques it has become feasible to review many taxa simultaneously to either identify cases of previously unsuspected variation or to define genetic lineages in complex taxa. Once an initial molecular screening has occurred, a further review of morphology, habitat, ecology, etc., need only be undertaken in cases where it is deemed warranted. Whilst these more detailed analyses are occurring, the taxa in question can at least be considered in any planning process, potentially protecting irreplaceable genetic diversity. This approach can help to prioritise scarce resources within taxonomy and better assist conservation efforts.

\section{ACKNOWLEDGMENTS}

The first author was funded by the Department of Environment and Conservation (DEC) through the South-West Catchment Council and the School of Natural Sciences and Centre for Ecosystem Management at Edith Cowan University, while in receipt of an Australian Postgraduate Award. The second author was supported by the Australian Rivers Institute and the School of Environment at Griffith University, while in receipt of an Australian Postgraduate Award. Sincere thanks are given to two anonymous reviewers and the editor whose comments greatly improved this manuscript.

\section{LITERATURE CITED}

Austin CM (1979). Biochemical systematics of the genus Cherax (Decapoda: Parastacidae). Honours Thesis. University of Western Australia, Perth, Australia.

Austin CM (1986). Electrophoretic and morphological systematic studies of the genus Cherax (Decapoda: Parastacidae) in Australia. PhD Thesis. University of Western Australia, Perth, Australia.

Austin CM (1996). Systematics of the freshwater crayfish genus Cherax Erichson (Decapoda: Parastacidae) in northern and eastern Australia: Electrophoretic and morphological variation. Australian Journal of Zoology 44(3):259-296.

Austin CM and KnotT B (1996). Systematics of the freshwater crayfish genus Cherax Erichson (Decapoda: Parastacidae) in south-western Australia: Electrophoretic, morphological and habitat variation. Australian Journal of Zoology 44(3):223258.

Austin CM and RyAn SG (2002). Allozyme evidence for a new species of freshwater crayfish of the genus Cherax Erichson (Decapoda: Parastacidae) from the south-west of Western Australia. Invertebrate Systematics 16(3):357-367.

Baker AM, Hughes JM, DeAn JC and Bunn SE (2004). Mitochondrial DNA reveals phylogenetic structuring and cryptic diversity in Australian freshwater macroinvertebrate assemblages. Marine and Freshwater Research 55(6):629640.

Balian EV, Lévéque C, Segers H and Martens K (2008). The freshwater animal diversity assessment: An overview of the results. Hydrobiologia 595:627-637.

Browning TL, Taggart DA, Rummery C, Close RL and Eldridge MDB (2001). Multifaceted genetic analysis of the "Critically Endangered" brush-tailed rock-wallaby Petrogale penicillata in Victoria, Australia: Implications for management. Conservation Genetics 2(2):145-156.

BURNHAM QF (2005). The systematics of the reducta complex of the burrowing freshwater crayfish Engaewa Riek. Honours Thesis. Edith Cowan University, Perth, Australia.

Burnham QF, Koenders A and Horwitz P (2012). The status of the critically endangered freshwater crayfish Engaewa pseudoreducta (Crustacea: Parastacidae) in south-western Australia. Records of the Western Australian Museum 27:45-54.

Campbell NJH, Geddes MC and Adams M (1994). Genetic variation in Yabbies, Cherax destructor and $C$. albidus (Crustacea: Decapoda: Parastacidae), indicates the presence of a single, highly sub-structured species. Australian Journal of Zoology 42(6):745-760. 
Cataudella R, Paolucci M, Delaunay C, Ropiquet A, Hassanin A, BALSAMO M and GRANDJEAN F (2010). Genetic variability of Austropotamobius italicus in the Marches region: implications for conservation. Aquatic Conservation: Marine and Freshwater Ecosystems 20(3):261-268.

Clark E (1936). The freshwater and land crayfishes of Australia. Memoirs of the National Museum of Victoria 10:5-58.

Clark E (1939). Tasmanian Parastacidae. Papers and Proceedings of the Royal Society of Tasmania April 1939:117-127.

Clark E and Burnet FM (1942). The application of serological methods to the study of the Crustacea. Australian Journal of Experimental Biology and Medical Science 20:89-95.

Coughran J, Dawkins KL and Furse JM (2010). Tenuibranchiurus glypticus. In: IUCN 2011. IUCN Red List of Threatened Species. Version 2011.2. www.iucnredlist.org. [accessed 23 March 2012].

Crandall K and Buhay J (2008). Global diversity of crayfish (Astacidae, Cambaridae, and Parastacidae-Decapoda) in freshwater. Hydrobiologia 595(1):295-301.

Crandall KA, Bininda-Emonds ORP, Mace GM and Wayne RK (2000). Considering evolutionary processes in conservation biology. Trends in Ecology \& Evolution 15(7):290-295.

Davie P (2007). Crustaceans. Pp. 428, In: Wildlife of Greater Brisbane. Ryan M (ed.) Queensland Museum, Brisbane, Australia.

DAWKINS KL and FurSE JM (2012). Conservation genetics as a tool for conservation and management of the native Japanese freshwater crayfish Cambaroides japonicus (de Haan). Crustacean Research, Special Number 7:35-43.

Dawkins KL, Furse JM, Wild CH and Hughes JM (2010). Distribution and population genetics of the threatened freshwater crayfish genus Tenuibranchiurus (Decapoda: Parastacidae). Marine and Freshwater Research 61(9):10481055.

DAYRAT B (2005). Towards integrative taxonomy. Biological Journal of the Linnean Society 85(3):407-415.

DeSalle R and Amato G (2004). The expansion of conservation genetics. Nature Reviews Genetics 5(9):702-712.

DeWoody JA and Avise JC (2000). Microsatellite variation in marine, freshwater and anadromous fishes compared with other animals. Journal of Fish Biology 56(3):461-473.

Dimmock A, Williamson I and Mather PB (2004). The influence of environment on the morphology of Macrobrachium australiense (Decapoda: Palaemonidae). Aquaculture International 12(4):435-456.

DiRzo R and Raven PH (2003). Global state of biodiversity and loss. Annual Review of Environment and Resources 28(1):137-167.

Dudgeon D, Arthington AH, Gessner MO, Kawabata Z-I, Knowler DJ, Lévêque C, Naiman RJ, Prieur-Richard A-H, Soto D, Stiassny MLJ and Sullivan CA (2006). Freshwater biodiversity: importance, threats, status and conservation challenges. Biological Reviews 81(2):163-182.
Edwards DL, Roberts JD and KeOgh JS (2007). Impact of Plio-Pleistocene arid cycling on the population history of a southwestern Australian frog. Molecular Ecology 16(13):2782-2796.

Fetzner JW and Crandall KA (2002). Genetic Variation. Pp. 291326, In: Biology of Freshwater Crayfish. Holdich DM (ed.) Blackwell Sciences, Oxford, UK.

Gaston KJ (1994). Rarity. Chapman \& Hall, London.

GASTON KJ and KunIN WE (1997). Rare-common differences: an overview. Pp. 12-29, In: The biology of rarity: causes and consequences of rare-common differences. Kunin WE and Gaston KJ (eds.). Chapman \& Hall, London, UK.

GoDFraY HCJ (2002). Challenges for taxonomy. Nature 417:1719.

HANSEN B and Richardson AMM (2006). A revision of the Tasmanian endemic freshwater crayfish genus Parastacoides (Crustacea: Decapoda: Parastacidae). Invertebrate Systematics 20(6):713-769.

HARVEY MS (2002). Short-range endemism among the Australian fauna: Some examples from non-marine environments. Invertebrate Systematics 16:555-570.

Hebert PDN, Cywinska A, Ball SL and deWaArd JR (2003). Biological identifications through DNA barcodes. Proceedings of the Royal Society of London. Series B: Biological Sciences 270(1512):313-321.

Henle K, Poschlod P, Margules C and Settele J (1996). Species Survival in Relation to Habitat Quality, Size, and Isolation: Summary Conclusions and Future Directions. Pp. 373-381, In: Species Survival in Fragmented Landscapes. Settele J, Margules C, Poschlod P and Henle K (eds.). Kluwer Academic, Netherlands.

HobBs JR. HH (1975). Adaptations and convergence in North American crayfish. Freshwater Crayfish 2:541-551.

HobBs JR. HH (1987). A review of the crayfish genus Astacoides (Decapoda: Parastacidae). Smithsonian Institution Press, Washington, DC.

Hobis JR. HH (1989). An Illustrated Checklist of the American Crayfishes (Decapoda: Astacidae, Cambaridae, and Parastacidae). Smithsonian Contributions to Zoology 480:1236.

Horwitz P (1988). Secondary Sexual Characteristics of Females of the Freshwater Crayfish Genus Engaeus (Decapoda, Parastacidae). Crustaceana 54(1):25-32.

Horwitz P (1995). A preliminary key to the species of Decapoda (Crustacea: Malacostraca) found in Australian inland waters. Co-operative Research Centre for Freshwater Ecology, Albury, Australia.

Horwitz P (2010). The conservation status of freshwater crayfish: the basis of concern, listing and recovery processes, and community involvement. Freshwater Crayfish 17:1-12.

Horwitz P and Adams M (2000). The systematics, biogeography and conservation status of species in the freshwater crayfish 
genus Engaewa Riek (Decapoda: Parastacidae) from southwestern Australia. Invertebrate Taxonomy 14(5):655-680.

Horwitz P, AdAms M and Baverstock P (1990). Electrophoretic contributions to the systematics of the freshwater crayfish genus Engaeus Erichson (Decapoda: Parastacidae). Invertebrate Systematics 4(3):615-641.

Horwitz P, Bradshaw D, Hopper S, Davies P, Froend R and BRADSHAW F (2008). Hydrological change escalates risk of ecosystem stress in Australia's threatened biodiversity hotspot. Journal of the Royal Society of Western Australia 91(1):1-11.

Huey JA, BAKer AM and Hughes JM (2010). High levels of genetic structure in the Australian freshwater fish, Ambassis macleayi. Journal of the North American Benthological Society 29(3):1148-1160.

Hughes JM (2007). Constraints on recovery: using molecular methods to study connectivity of aquatic biota in rivers and streams. Freshwater Biology 52(4):616-631.

IUCN (2011). IUCN Red List of Threatened Species. Version 2011.2. http://www.iucnredlist.org. [Accessed 23 March 2012].

Linkem CW, Hesed KM, Diesmos AC and Brown RM (2010). Species boundaries and cryptic lineage diversity in a Philippine forest skink complex (Reptilia; Squamata; Scincidae: Lygosominae). Molecular Phylogenetics and Evolution 56(2):572-585.

MAIN BY (1996). Terrestrial invertebrates in south-west Australian forests: the role of relict species and habitats in reserve design. Journal of the Royal Society of Western Australia 79:277-280.

Mallett J and Willmott K (2003). Taxonomy: renaissance or Tower of Babel. Trends in Ecology and Evolution 18:57-59.

MAURER BA and NotT MP(1998). Geographic range fragmentation and the evolution of biological diversity. Pp. 31-50, In: Biodiversity dynamics. McKinney ML and Drake JA (eds.). Columbia University Press, New York.

MAY RM (2010). Ecological science and tomorrow's world. Philosophical Transactions of the Royal Society B: Biological Sciences 365(1537):41-47.

MefFe GK and VRiJenhoek RC (1988). Conservation Genetics in the Management of Desert Fishes. Conservation Biology 2(2):157-169.

Morgan GJ (1986). Freshwater crayfish of the genus Euastacus Clark (Decapoda: Parastacidae) from Victoria. Memoirs of the Museum of Victoria 47:1-57.

Morgan GJ (1988). Freshwater crayfish of the genus Euastacus Clark (Decapoda: Parastacidae) from Queensland. Memoirs of the Museum of Victoria 49:1-49.

Moritz C (1994). Defining 'Evolutionarily Significant Units’ for conservation. Trends in Ecology \& Evolution 9(10):373-375.

Nei Mand Kumar S (2000). Molecular Evolution and Phylogenetics. Oxford University Press, New York.

Nguyen TTT, Meewan M, Ryan S and Austin CM (2002). Genetic diversity and translocation in the marron, Cherax tenuimanus
(Smith): implications for management and conservation. Fisheries Management and Ecology 9(3):163-173.

PATAKAandBALDWINJ(1984).Electrophoreticandimmunochemical comparisons of haemocyanins from Australian fresh-water crayfish (Family Parastacidae): phylogenetic implications. Journal of Crustacean Biology 4(4):528-535.

PATAK A, BALDWIN J and LAKE PS (1989). Immunochemical comparisons of haemocyanins of Australasian freshwater crayfish: Phylogenetic implications. Biochemical Systematics and Ecology 17(3):249-252.

RAm M and Dewhurst N (2008). All Crayfish and Lobsters to hit Red List. Crayfish News 30(1):16-17.

RICHARDSON AMM and SWAIN R (1980). Habitat requirements and distribution of Engaeus cisternarius and three subspecies of Parastacoides tasmanicus (Decapoda: Parastacidae), burrowing crayfish from an area of south-western Tasmania. Marine and Freshwater Research 31(4):475-484.

RIEK EF (1951). The freshwater crayfish (family Parastacidae) of Queensland. With an appendix describing other Australian species. Records of the Australian Museum 22(4):368-388.

RiEK EF (1956). Additions to the Australian freshwater crayfish. Records of the Australian Museum 24(1):1-6.

RIEK EF (1967a). The Tasmanian freshwater crayfish genus Parastacoidea (Decapoda: Parastacidae). Australian Journal of Zoology 15(5):999-1006.

RIEK EF (1967b). The freshwater crayfish of Western Australia (Decapoda: Parastacidae). Australian Journal of Zoology 15(1):103-121.

RIEK EF (1969). The Australian freshwater crayfish (Crustacea: Decapoda: Parastacidae), with descriptions of a new species. Australian Journal of Zoology 17(5):855-918.

RIEK EF (1972). The phylogeny of the Parastacidae (Crustacea: Astacoidea), and description of a new genus of Australian freshwater crayfishes. Australian Journal of Zoology 20(4):369-389.

Rossiter A and Kawanabe H (2000). Ancient lakes: biodiversity, ecology and evolution. Academic, San Diego, California.

SalaOE,Stuart ChapinF,III,ArmestoJJ,BerlowE,Bloomfield J, Dirzo R, Huber-Sanwald E, Huenneke LF, Jackson RB, Kinzig A, Leemans R, Lodge DM, Mooney HA, Oesterheld MÃ, Poff NL, Sykes MT, Walker BH, Walker M and Wall DH (2000). Global Biodiversity Scenarios for the Year 2100. Science 287(5459):1770-1774.

Sgrò CM, Lowe AJ and Hoffmann AA (2011). Building evolutionary resilience for conserving biodiversity under climate change. Evolutionary Applications 4(2):326-337.

Sinclair EA, Madsen A, Walsh T, Nelson J and Crandall KA (2011). Cryptic genetic divergence in the giant Tasmanian freshwater crayfish Astacopsis gouldi (Decapoda: Parastacidae): implications for conservation. Animal Conservation 14(1):87-97.

Stoeckle M (2003). Taxonomy, DNA, and the Bar Code of Life. Bioscience 53(9):796-797. 
STORK NE (1994). Inventories of Biodiversity: More Than a Question of Numbers. Pp. 81-100, In: Systematics and Conservation Evaluation. Forey PL, Humphries CJ and VaneWright RI (eds.). Oxford University Press, New York, USA.

STRAYER DL (2006). Challenges for freshwater invertebrate conservation. Journal of the North American Benthological Society 25(2):271-287.

Strayer DL and Dudgeon D (2010). Freshwater biodiversity conservation: recent progress and future challenges. Journal of the North American Benthological Society 29(1):344-358.

Sumner CE (1978). A revision of the genus Parastacoides Clark (Crustacea: Decapoda: Parastacidae). Australian Journal of Zoology 26(4):809-821.

SwAIN R, RichardSONAMM and HoRTLE M (1982). Revison of the Tasmanian genus of freshwater crayfish Astacopsis Huxley (Decapoda: Parastacidae). Marine and Freshwater Research 33(4):699-709.

Valdecasas A, Williams D and Wheeler QD (2008). 'Integrative taxonomy' then and now: a response to Dayrat (2005). Biological Journal of the Linnean Society. Linnean Society of London 93(1):211-216.

Ward RD, Zemlak TS, Innes BH, Last PR and Hebert PDN (2005). DNA barcoding Australia's fish species. Philosophical Transactions of the Royal Society B: Biological Sciences 360(1462):1847-1857.

Will KW, Mishler BD and Wheeler QD (2005). The Perils of DNA Barcoding and the Need for Integrative Taxonomy. Systematic Biology 54(5):844.

Zeidler W and Adams M (1990). Revision of the Australian crustacean genus of freshwater crayfish Gramastacus Riek (Decapoda: Parastacidae). Invertebrate Systematics 3(7):913924. 
